\title{
High bone turnover elevates the risk of denosumab-induced hypocalcemia in women with postmenopausal osteoporosis
}

This article was published in the following Dove Press journal:

Therapeutics and Clinical Risk Management

5 December 2016

Number of times this article has been viewed

\author{
Koji Ishikawa' \\ Takashi Nagai' \\ Keizo Sakamoto' \\ Kenji Ohara ${ }^{2}$ \\ Takeshi Eguro ${ }^{1,2}$ \\ Hiroshi Ito' \\ Yoichi Toyoshima' \\ Akatsuki Kokaze ${ }^{3}$ \\ Tomoaki Toyone' \\ Katsunori Inagaki' \\ 'Department of Orthopaedic Surgery, \\ Showa University School of Medicine, \\ Tokyo, ${ }^{2}$ Department of Orthopaedic \\ Surgery, Yamanashi Red Cross \\ Hospital, Yamanashi, ${ }^{3}$ Department \\ of Public Health, Showa University \\ School of Medicine, Tokyo, Japan
}

Correspondence: Koji Ishikawa

Department of Orthopaedic Surgery,

Showa University School of Medicine,

I-5-8 Hatanodai, Shinagawa-ku,

Tokyo I42-8666, Japan

Tel +8I 337848543

Fax +8I 337849005

Email o9ol6979696koji@gmail.com

\begin{abstract}
Hypocalcemia is the most common major adverse event in patients with osteoporosis receiving the bone resorption inhibitor denosumab; however, limited information is available regarding risk factors of hypocalcemia. Therefore, this study aimed to identify the risk factors of hypocalcemia induced by denosumab treatment for osteoporosis. We retrospectively reviewed the records of patients who had received initial denosumab supplemented with activated vitamin D for osteoporosis. Serum levels of the following bone turnover markers (BTMs) were measured at baseline: bone-specific alkaline phosphatase (BAP), total N-terminal propeptide of type 1 procollagen (P1NP), tartrate-resistant acid phosphatase 5b (TRACP-5b), and urinary cross-linked N-telopeptide of type 1 collagen (NTX). Of the 85 denosumab-treated patients with osteoporosis studied, 22 (25.9\%) developed hypocalcemia. Baseline serum total P1NP, TRACP-5b, and urinary NTX were significantly higher in patients with hypocalcemia than in those with normocalcemia following denosumab administration (all $P<0.01$ ). Multivariate logistic regression analysis revealed that patients with total P1NP $>76.5 \mu \mathrm{g} / \mathrm{L}$, TRACP-5b $>474 \mathrm{mU} / \mathrm{dL}$, or urinary NTX $>49.5 \mathrm{nmol}$ bone collagen equivalent $/ \mathrm{mmol}$ creatinine had a higher risk of hypocalcemia $(P<0.01)$. Our study suggests that denosumab may have a greater impact on serum calcium levels in patients with postmenopausal osteoporosis with higher baseline bone turnover than in patients with postmenopausal osteoporosis with normal baseline bone turnover, because maintenance of normal serum calcium in this subgroup is more dependent on bone resorption. Close monitoring of serum calcium levels is strongly recommended for denosumab-treated patients with high bone turnover, despite supplementation with activated vitamin D and oral calcium.
\end{abstract}

Keywords: denosumab, hypocalcemia, bone turnover, osteoporosis

\section{Introduction}

Denosumab has been approved in various countries for treating patients with osteoporosis at a high risk of fracture and preventing skeletal-related events in patients with bone metastases from solid tumors. Denosumab is an entirely human monoclonal immunoglobulin (Ig) G2 antibody that binds to the receptor activator of nuclear factor $\kappa \mathrm{B}$ (RANK) ligand (RANKL). In men and postmenopausal women with osteoporosis, a single $60 \mathrm{mg}$ dose of denosumab subcutaneously administered every 6 months significantly reduces bone turnover markers (BTMs), increases bone mineral density (BMD), and reduces the risk of new vertebral and nonvertebral fractures, including hip fractures. ${ }^{1}$ Several studies have found that treatment with denosumab increases both BMD and bone strength as estimated by quantitative computed tomography of the radius, hip, and spine..$^{2,3}$ In a long-term clinical study, denosumab treatment increased 
BMD and decreased bone turnover for up to 8 years with an acceptable safety profile. ${ }^{4}$ Continuous denosumab treatment beyond 3 years was associated with a further persistent reduction in nonvertebral fracture rate. ${ }^{5}$ Economic evaluations have deemed denosumab cost-effective for osteoporosis treatment in men and women. ${ }^{6,7}$

Despite this demonstrated efficacy, several serious adverse effects of denosumab have been reported, including hypocalcemia ${ }^{8,9}$ in $2 \%-20 \%$ of women with postmenopausal osteoporosis $^{10,11}$ and $10 \%-50 \%$ of bone metastasis patients who were administered a single $120 \mathrm{mg}$ dose. ${ }^{12-14}$ Furthermore, in Phase III trials of a single $120 \mathrm{mg}$ dose, up to $33 \%$ of patients who experienced severe hypocalcemia had recurrent events despite oral supplementation with calcium and vitamin D. ${ }^{14}$

Although hypocalcemia is usually transient and asymptomatic, it can have serious manifestations, including cardiac arrhythmias and death. ${ }^{8,9}$ To prevent hypocalcemia following denosumab administration, prophylactic administration of calcium and/or vitamin $\mathrm{D}$ is recommended for osteoporosis and bone metastases patients unless albumin-adjusted serum calcium concentrations are high. ${ }^{15-18}$ While prophylactic administration of calcium and/or vitamin D is now deemed essential, reports of severe hypocalcemia despite calcium and vitamin D supplementation exist. ${ }^{8,11,17,18}$ Therefore, identification of potential risk factors for hypocalcemia is critical.

Block et $\mathrm{al}^{11}$ reported that the risk for denosumab-induced hypocalcemia was greater in osteoporosis patients with chronic kidney disease (CKD) than in patients with normal renal function, whereas renal function impairment did not significantly affect denosumab pharmacokinetics and pharmacodynamics. In patients with bone metastases, lower baseline estimated glomerular filtration rate (eGFR) is an important risk factor for hypocalcemia induced by denosumab. ${ }^{17,18}$ However, patients with both osteoporosis and bone metastases developed denosumab-induced severe hypocalcemia with mild-to-moderate CKD (30-89 mL/min/1.73 $\left.\mathrm{m}^{2}\right) .8,9,11$ Hypocalcemia induced by denosumab usually occurs 1-2 weeks after initial administration, whereas renal function is not altered over the entire course of denosumab treatment. ${ }^{14,19}$ Therefore, we hypothesized that other factors influence serum calcium concentrations in these patients. In the current study, we retrospectively analyzed a cohort of denosumab-treated postmenopausal osteoporosis patients to identify risk factors for hypocalcemia.

\section{Materials and methods Study design}

Between November 2014 and April 2015, 114 patients received initial administration of denosumab at Yamanashi Red Cross
Hospital (Yamanashi, Japan). In this retrospective study, the medical records of postmenopausal osteoporosis patients who received an initial denosumab injection and completed a clinicodemographic questionnaire were reviewed.

Patients were eligible for the study if they were $\geq 55$ years of age with postmenopausal osteoporosis and had received a single $60 \mathrm{mg}$ subcutaneous dose of denosumab (Prolia ${ }^{\circledR}$; Amgen Inc., Thousand Oaks, CA, USA) with daily supplementation of vitamin D. In our institution, we use eldecalcitol (activated vitamin D) at $0.75 \mu \mathrm{g}$ as a prophylactic drug for denosumab to avoid hypocalcemia induced by denosumab. A key inclusion criterion was blood sampling at baseline, 1-2 weeks, 1 month, 3 months, and 6 months after denosumab administration.

Patients were excluded from the study if they had 1) adjusted baseline serum calcium concentrations above or below the normal range in our laboratory $(8.7-10.3 \mathrm{mg} / \mathrm{dL})$; 2) severe CKD (eGFR $<30 \mathrm{~mL} / \mathrm{min}$ ) or required hemodialysis; 3) disorders such as primary hyperparathyroidism, Cushing's syndrome, or poorly controlled diabetes mellitus (glycated hemoglobin $[\mathrm{HbA} 1 \mathrm{C}]>7.5 \% 0^{20}$ ); 4) active malignant tumor; 5) received calcitonin replacement therapy or other medications that could affect serum calcium concentration; 6) fresh fracture or orthopedic surgery within a month before denosumab administration; 7) surgery during the first course of denosumab; or 8) received or were scheduled to receive any invasive dental procedures.

Of the initial cohort, 85 patients were eligible for the current study. The study was conducted with the approval of the ethics committee of the Yamanashi Red Cross Hospital and in accordance with the Declaration of Helsinki. The need for patient written informed consent was waived by the ethics committee because this is a retrospective study with data collection and analysis from the medical records.

\section{Data collection and assessment}

All data were collected from the electronic medical record system. We also evaluated information obtained from a baseline questionnaire, including age, weight, height, body mass index (BMI), previous fracture history, family history of fractures, smoking history, alcohol consumption, glucocorticoid use, other health conditions such as rheumatoid arthritis and diabetes mellitus, and prior treatment for osteoporosis. We evaluated serum levels of albumin, calcium, phosphorus, and alkaline phosphatase, as well as the eGFR, at baseline and at 1-2 weeks (median days [interquartile range, IQR]: 7.0 [7.0-7.0] days), 1 month (28.0 [28.0-32.0] days), 3 months (88.0 [84.0-92.0] days), and 6 months (179.0 [172.0-183.5] days) after treatment. 
Intact parathyroid hormone (intact $\mathrm{PTH}$; the reference range: $10-65 \mathrm{pg} / \mathrm{mL}$, estimated by Access ${ }^{\circledR}$ Intact PTH assay; Beckman Coulter Inc., Brea, CA, USA) and the following BTMs were also assessed at baseline and at 1 month, 3 months, and 6 months after treatment: bonespecific alkaline phosphatase (BAP; the reference range in postmenopausal women: $3.8-22.6 \mu \mathrm{g} / \mathrm{L}$, estimated by the Access Ostase Assay; Beckman Coulter Inc.), total N-terminal propeptide of type I procollagen (total P1NP; the reference range in postmenopausal women: $26.4-98.2 \mu \mathrm{g} / \mathrm{L}$; estimated by a total P1NP assay on the Elecsys automated analyzer; Roche Diagnostics, Basel, Switzerland), tartrateresistant acid phosphatase type 5 (TRACP-5b; the reference range in women: $120-420 \mathrm{mU} / \mathrm{dL}$; estimated by Osteolinks ${ }^{\circledR}$ TRACP-5b ${ }^{\circledR}$ Test Kit; DS Pharma Biomedical Co, Ltd, Osaka, Japan), and urine levels of cross-linked N-telopeptide of type I collagen (urinary NTX; the reference range in postmenopausal women: 14.3-89.0 nmol bone collagen equivalent $(\mathrm{BCE}) / \mathrm{mmol}$ creatinine $(\mathrm{Cr})$; Osteomark ${ }^{\circledR} \mathrm{NTx}$ Urine Assay; Alere Medical Co, Ltd, Tokyo, Japan). After overnight fasting, serum and urine samples were obtained in the early morning.

Vertebral fractures at baseline were diagnosed by lateral spine X-ray examination at the thoracic and lumbar levels and, in addition, were assessed quantitatively according to the criteria of the Japanese Society for Bone and Mineral Research. ${ }^{21}$ BMD of lumbar spine (L1-4), total hip, and femoral neck were also measured at baseline using dualenergy X-ray absorptiometry (DXA; Hologic QDR ${ }^{\text {TM }}$ series: Hologic, Waltham, MA, USA). All DXA measurements were analyzed at a central site by a radiologist.

Hypocalcemia was defined as an adjusted serum calcium concentration $<8.7 \mathrm{mg} / \mathrm{dL}$, the lower limit of the normal range at our central laboratory. If the serum albumin level was $<4.0 \mathrm{mg} / \mathrm{dL}$, the corrected calcium level was calculated according to the following equation: corrected serum calcium $=$ serum calcium $(\mathrm{mg} / \mathrm{dL})-$ serum albumin $(\mathrm{mg} / \mathrm{dL})+4.0$. The severity of hypocalcemia was classified according to the National Cancer Institutes Common Toxicity Criteria for Adverse Events version 4.0. If a patient was administered denosumab several times within the study period, only the change in serum calcium level after the first administration was used to determine hypocalcemia. The eGFR level was calculated using the formula developed by the Japanese Society of Nephrology. ${ }^{22}$ The primary end point was to identify the risk factors associated with denosumabinduced hypocalcemia. The secondary end point was to determine the time course of change in serum calcium concentration following initial denosumab administration.

\section{Statistical analysis}

The $\chi^{2}$ test was used to compare categorical variables. Continuous variables with normal distribution are presented as mean \pm standard deviation (SD), whereas nonnormally distributed variables are presented as median with IQR. Student's $t$-test was used to compare group means for normally distributed variables, and Mann-Whitney $U$ test was used to compare group means for nonnormally distributed variables. Mean differences in concentrations of serum calcium and intact PTH from baseline following initial denosumab treatment were compared using one-way analysis of variance followed by Dunnett's test. The correlations between baseline BTMs and both serum calcium concentration nadir and change from baseline to nadir following the first denosumab treatment were determined using Pearson's coefficients. Univariate and multivariate logistic analyses were performed to identify risk factors for hypocalcemia associated with denosumab. A receiver operating characteristic (ROC) curve was used to calculate the optimal cutoff values for factors obtained by univariate logistic analysis. Multiple logistic regression analyses were used to calculate the odds ratios (ORs) for hypocalcemia induced by denosumab. Covariates were selected for their ability to confound the associations as determined through univariate and stepwise models. Statistical analyses were performed using Stat Flex version 6 (Artech, Tokyo, Japan) and GraphPad PRISM version 6 (GraphPad Software, San Diego, CA, USA). All statistical tests were two tailed and $P$-values $<0.05$ were considered statistically significant.

\section{Results}

\section{Baseline patient characteristics}

All 85 postmenopausal osteoporosis patients received denosumab treatment plus prophylactic eldecalcitol at baseline. Mean age was $75.7 \pm 8.0$ years (range: $56-91$ years) and BMI was $22.3 \pm 4.1 \mathrm{~kg} / \mathrm{m}^{2}$ (range: $13.4-37.5 \mathrm{~kg} / \mathrm{m}^{2}$ ). Moreover, 45 patients $(52.9 \%)$ had a history of previous fracture. Few patients had disorders such as rheumatoid arthritis ( 3 patients, $3.5 \%$ ) or diabetes mellitus (4 patients, $4.7 \%$ ). Among the 85 patients, $23(27.1 \%)$ had received prior treatment for osteoporosis, including bisphosphonate (14 patients, 16.5\%), activated vitamin D (2 patients, 2.4\%), a selective estrogen receptor modulator ( 2 patients, $2.4 \%$ ), or teriparatide (5 patients, 5.9\%). Baseline serum albumin, calcium, phosphorus, alkaline phosphatase, and intact PTH values were all within normal ranges. Renal function was normal or mildly dysfunctional (eGFR: $\geq 60 \mathrm{~mL} / \mathrm{min}$ ) in 58 patients $(68.2 \%)$, whereas 27 patients $(31.8 \%)$ had moderate kidney 
dysfunction (eGFR: 30-59 mL/min). The BTMs BAP, total P1NP, TRACP-5b, and urinary NTX were all higher than the upper limit of the normal premenopausal range. Baseline lumbar, femoral neck, and total hip BMD $T$-scores were $-2.4 \pm 1.2,-3.0 \pm 1.1$, and $-2.6 \pm 1.2$, respectively.

\section{Time course of changes in serum calcium and intact PTH concentrations following denosumab treatment}

None of the patients were hypocalcemic at baseline, but 22 (25.9\%) developed hypocalcemia following administration of a single $60 \mathrm{mg}$ subcutaneous dose of denosumab. Figure 1 displays the time courses of changes in albumin-adjusted serum calcium and intact PTH concentrations from baseline during the 6 months following the first denosumab treatment. Serum calcium concentration decreased from $9.3 \pm 0.4 \mathrm{mg} / \mathrm{dL}$ (range: $8.7-10.2 \mathrm{mg} / \mathrm{dL}$ ) at baseline to $9.0 \pm 0.5 \mathrm{mg} / \mathrm{dL}$ (range: 7.6-10.3 mg/dL) during the first 1-2 weeks before returning to baseline (1 month: $9.2 \pm 0.5 \mathrm{mg} / \mathrm{dL}$, range: $8.4-10.4 \mathrm{mg} / \mathrm{dL}$; 3 months: $9.3 \pm 0.4 \mathrm{mg} / \mathrm{dL}$, range: $8.4-10.7 \mathrm{mg} / \mathrm{dL} ; 6$ months: 9.4 $\pm 0.5 \mathrm{mg} / \mathrm{dL}$, range: $8.7-10.9 \mathrm{mg} / \mathrm{dL}$ ). Serum intact PTH concentration increased from $47.6 \pm 22.3 \mathrm{pg} / \mathrm{mL}$ (range: $10.2-110.0 \mathrm{pg} / \mathrm{mL}$ ) at baseline to $59.5 \pm 44.2 \mathrm{pg}$ / $\mathrm{mL}$ (range: $6.0-248.0 \mathrm{pg} / \mathrm{mL}$ ) during the first 1 month and then decreased between 3 months and 6 months ( 3 months: $48.0 \pm 33.8 \mathrm{pg} / \mathrm{mL}$, range: $12.0-196.0 \mathrm{pg} / \mathrm{mL}$; 6 months: $39.5 \pm 23.9 \mathrm{pg} / \mathrm{mL}$, range: $8.0-111.0 \mathrm{pg} / \mathrm{mL})$. Hypocalcemia lasted 1-2 weeks in 16 of 22 patients $(72.7 \%), 1$ month in 5 patients $(22.7 \%)$, and 3 months in 1 patient (4.5\%). Twentyone of the hypocalcemic patients were grade 1 and only one was grade 2 . All hypocalcemic patients received temporary oral calcium (1,000-3,000 mg/daily) and were asymptomatic.
The serum calcium concentrations normalized immediately after oral calcium. Hypercalcemia $>10.3 \mathrm{mg} / \mathrm{dL}$ (above the normal range in our laboratory) was observed at least once in 5 patients $(5.9 \%)$ and they recovered quickly after the discontinuation of eldecalcitol.

\section{Comparison of clinical parameters between hypocalcemic and normocalcemic patients}

None of the demographic parameters in Table 1 differed significantly between patients exhibiting hypocalcemia following denosumab treatment and those maintaining normocalcemia, except for mean serum calcium concentration $(9.1 \pm 0.2 \mathrm{mg} / \mathrm{dL}$ vs $9.4 \pm 0.4 \mathrm{mg} / \mathrm{dL}, P=0.002$ ) and 3 of the 4 BTMs (total P1NP: $100.4 \pm 58.2 \mu \mathrm{g} / \mathrm{L}$ vs $60.0 \pm 34.4 \mu \mathrm{g} / \mathrm{L}, P<0.001$; TRACP-5b: $596.1 \pm 209.6 \mathrm{mU} / \mathrm{dL}$ vs $450.9 \pm 177.2 \mathrm{mU} / \mathrm{dL}$, $P=0.002$; urinary NTX: $76.4 \pm 38.9 \mathrm{nmol} \mathrm{BCE} / \mathrm{mmol} \mathrm{Cr}$ vs $48.4 \pm 27.6 \mathrm{nmol} \mathrm{BCE} / \mathrm{mmol} \mathrm{Cr}, P<0.001)$. These results strongly suggest that higher bone turnover, as evidenced by higher total P1NP, TRACP-5b, and urine NTX, increases the risk of denosumab-induced hypocalcemia.

\section{Correlations between serum calcium concentration and baseline BTMs}

Negative correlations were observed between the serum calcium concentration nadir after denosumab administration and the baseline total P1NP ( $r=-0.409, P<0.001)$, TRACP-5b $(r=-0.353, P<0.001)$, and urinary NTX ( $r=-0.468, P<0.001$; Figure 2A, subpanels 2-4), consistent with an association between bone turnover rate and hypocalcemia risk. Furthermore, negative correlations were observed between the change in serum calcium concentration from baseline to
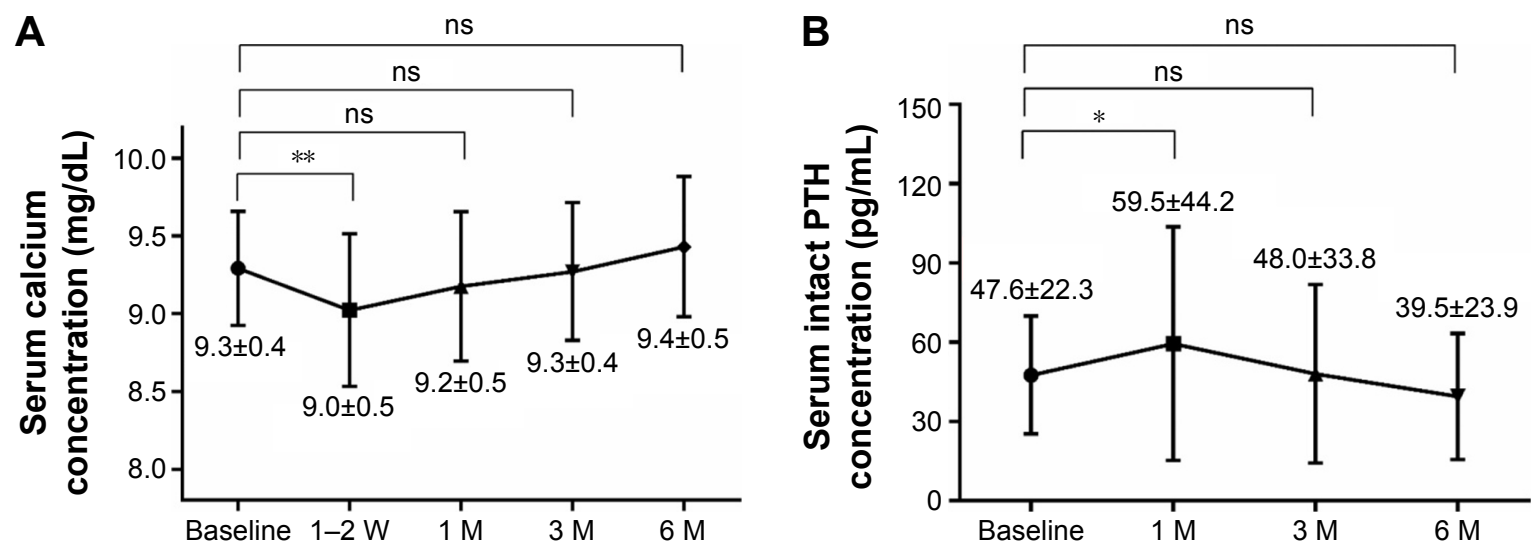

Figure I Time course of changes in (A) serum calcium and (B) intact PTH concentrations following single-dose denosumab.

Notes: Data are expressed as mean \pm SD and compared using one-way analysis of variance, followed by Dunnett's test. $* P<0.05 ; * * P<0.01$.

Abbreviations: M, months; ns, nonsignificant; PTH, parathyroid hormone; SD, standard deviation; W, weeks. 
Table I Comparison of clinical parameters between hypocalcemic and normocalcemic patients

\begin{tabular}{|c|c|c|c|}
\hline Parameters & $\begin{array}{l}\text { Hypocalcemia } \\
(n=22)\end{array}$ & $\begin{array}{l}\text { No hypocalcemia } \\
(n=63)\end{array}$ & $P$-value \\
\hline Age (years), mean \pm SD & $75.7 \pm 7.9$ & $75.8 \pm 8.1$ & 0.968 \\
\hline Height $(m)$, mean $\pm S D$ & $\mathrm{I} .5 \mathrm{I} \pm 0 . \mathrm{I}$ & $1.49 \pm 0.1$ & 0.344 \\
\hline Body weight $(\mathrm{kg})$, mean $\pm S D$ & $50.0 \pm 10.3$ & $49.9 \pm 8.9$ & 0.960 \\
\hline Body mass index $\left(\mathrm{kg} / \mathrm{m}^{2}\right)$, mean \pm SD & $21.9 \pm 4.3$ & $22.5 \pm 4.0$ & 0.614 \\
\hline History of previous fracture, $n(\%)$ & $8(36.4)$ & $37(58.7)$ & 0.070 \\
\hline Current smoker, n (\%) & I (4.5) & $3(4.8)$ & 0.967 \\
\hline Alcohol consumption, $\mathrm{n}(\%)$ & $0(0)$ & $\mathrm{I}(\mathrm{I} .6)$ & 0.552 \\
\hline Rheumatoid arthritis, n (\%) & I (3.7) & $2(3.7)$ & 0.764 \\
\hline \multicolumn{4}{|l|}{ Prior treatment for osteoporosis } \\
\hline Bisphosphonate, n (\%) & $2(9.1)$ & $12(19.0)$ & 0.278 \\
\hline Vitamin D, n (\%) & $\mathrm{I}(4.5)$ & $2(3.2)$ & 0.764 \\
\hline SERM, n (\%) & $0(0)$ & $\mathrm{I}(\mathrm{I} .6)$ & 0.552 \\
\hline Teriparatide, n (\%) & $0(0)$ & $5(7.9)$ & 0.173 \\
\hline Albumin $(\mathrm{mg} / \mathrm{dL})$, mean $\pm \mathrm{SD}$ & $4.2 \pm 0.3$ & $4.3 \pm 0.3$ & 0.482 \\
\hline Calcium (mg/dL), mean \pm SD & $9.1 \pm 0.2$ & $9.4 \pm 0.4$ & $0.002 *$ \\
\hline Phosphorus (mg/dL), mean \pm SD & $3.6 \pm 0.4$ & $3.5 \pm 0.4$ & 0.384 \\
\hline Alkaline phosphatase (U/L), mean $\pm S D$ & $288.3 \pm 110.6$ & $278.4 \pm 102.1$ & 0.702 \\
\hline eGFR $(\mathrm{mL} / \mathrm{min})$, mean $\pm \mathrm{SD}$ & $71.4 \pm 15.4$ & $67.6 \pm 18.0$ & 0.389 \\
\hline Intact PTH $(\mathrm{pg} / \mathrm{mL})$, mean \pm SD & $46.8 \pm 20.3$ & $47.8 \pm 23.1$ & 0.850 \\
\hline $\operatorname{BAP}(\mu g / L)$, mean \pm SD & $22.0 \pm 9.2$ & $19.4 \pm 9.5$ & 0.263 \\
\hline Total PINP $(\mu \mathrm{g} / \mathrm{L})$, mean \pm SD & $100.4 \pm 58.2$ & $60.0 \pm 34.4$ & $<0.00 I^{*}$ \\
\hline TRACP-5b $(\mathrm{mU} / \mathrm{dL})$, mean $\pm \mathrm{SD}$ & $596.1 \pm 209.6$ & $450.9 \pm 177.2$ & $0.002 *$ \\
\hline Urinary NTX (nmol BCE/mmol Cr), mean \pm SD & $76.4 \pm 38.9$ & $48.4 \pm 27.6$ & $<0.00 I^{*}$ \\
\hline Lumbar BMD ( $T$-score), mean \pm SD & $-2.0 \pm 1.0$ & $-2.5 \pm 1.3$ & 0.117 \\
\hline Femoral neck BMD (T-score), mean \pm SD & $-3.1 \pm 0.9$ & $-3.0 \pm 1.1$ & 0.882 \\
\hline Total hip BMD (T-score), mean \pm SD & $-2.6 \pm 0.9$ & $-2.6 \pm 1.2$ & 0.930 \\
\hline \multicolumn{4}{|l|}{ Day on which blood sample was drawn after } \\
\hline \multicolumn{4}{|l|}{ administration of denosumab (median day [IQR]) } \\
\hline I-2 weeks & $7.0(7.0-7.0)$ & $7.0(7.0-7.0)$ & 0.737 \\
\hline I month & $28.0(28.0-28.0)$ & $28.0(28.0-32.0)$ & 0.084 \\
\hline 3 months & $84.5(84.0-91.0)$ & $91.0(84.0-93.5)$ & 0.140 \\
\hline 6 months & $176.0(169.0-183.0)$ & $179.0(\mid 75.0-184.5)$ & 0.467 \\
\hline
\end{tabular}

Notes: Data shown as $\mathrm{n}$ or $\mathrm{n}(\%)$ were analyzed by $\chi^{2}$ test. Data expressed as mean \pm SD were analyzed by the Student's $t$-test. Data presented as median (IQR) were analyzed by the Mann-Whitney $U$ test. ${ }^{*} P<0.05$.

Abbreviations: BAP, bone-specific alkaline phosphatase; BCE, bone collagen equivalent; BMD, bone mineral density; Cr, creatinine; eGFR, estimated glomerular filtration rate; IQR, interquartile range; NTX, cross-linked N-telopeptide of type I collagen; PINP, N-terminal propeptide of type I procollagen; PTH, parathyroid hormone; $\mathrm{SD}$, standard deviation; SERM, selective estrogen receptor modulator; TRACP-5b, tartrate-resistant acid phosphatase $5 \mathrm{~b}$.

nadir and baseline BAP $(r=-0.317, P=0.003)$, total P1NP $(r=-0.454, P<0.001)$, TRACP-5b $(r=-0.392, P<0.001)$, and urinary NTX $(r=-0.385, P<0.001)$ (Figure 2B, subpanels 1-4).

\section{Univariate and ROC curve analyses}

Univariate logistic regression analysis revealed significant associations between hypocalcemia incidence and total P1NP, TRACP-5b, and urinary NTX (Table 2). To estimate the power of these BTMs to predict denosumab-induced hypocalcemia, the areas under the ROC curves (AUCs) obtained by univariate logistic regression analyses were calculated. ROC curve analysis indicated that a baseline total P1NP $>76.5 \mu \mathrm{g} / \mathrm{L}$ was the strongest predictor (AUC $=0.76)$ of hypocalcemia. Using a cutoff value of
$76.5 \mu \mathrm{g} / \mathrm{L}$, the sensitivity for predicting hypocalcemia was $68.2 \%$ and the specificity was $79.4 \%$. Similarly, baseline TRACP-5b $>474 \mathrm{mU} / \mathrm{dL}(\mathrm{AUC}=0.71)$ and baseline urinary NTX $>49.5 \mathrm{nmol} \mathrm{BCE} / \mathrm{mmol} \mathrm{Cr}(\mathrm{AUC}=0.74)$ were useful predictors of hypocalcemia.

\section{Multivariate logistic regression analysis for hypocalcemia}

Multivariate logistic regression analysis (Table 3 ) identified total P1NP, TRACP-5b, and urinary NTX as independent predictors of denosumab-induced hypocalcemia. Moreover, these significant ORs remained after adjustment for baseline serum calcium concentration and eGFR (total P1NP > 76.5 $\mu \mathrm{g} / \mathrm{L}: \mathrm{OR}$ $=10.600,95 \%$ confidence interval $[\mathrm{CI}]: 3.070-36.598$, $P<0.001$; TRACP-5b $>474 \mathrm{mU} / \mathrm{dL}:$ OR $=4.596,95 \%$ 
A 1
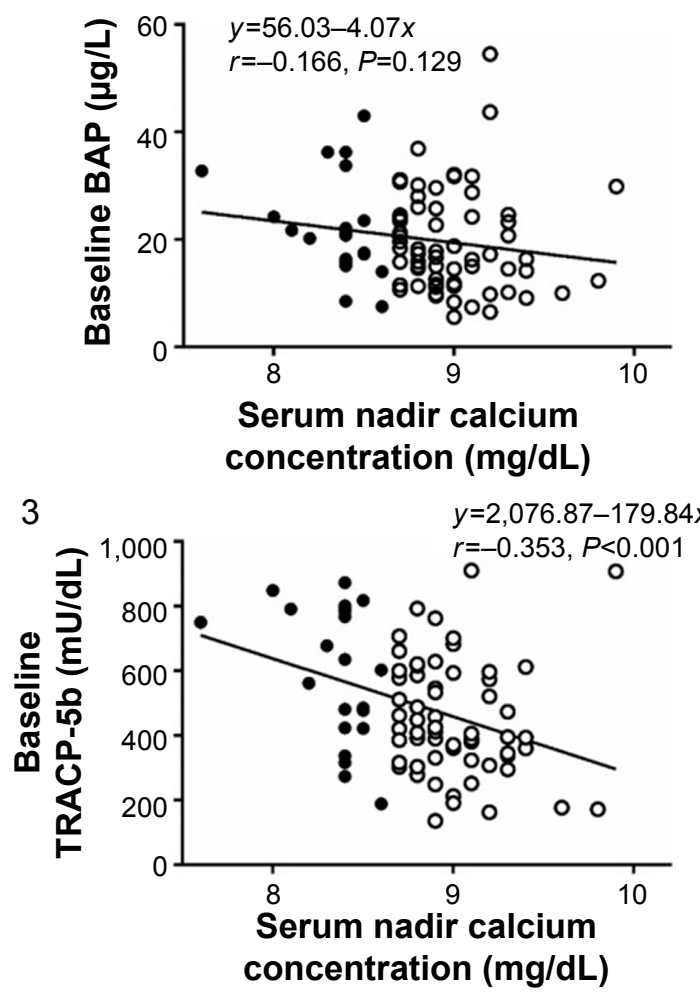

B

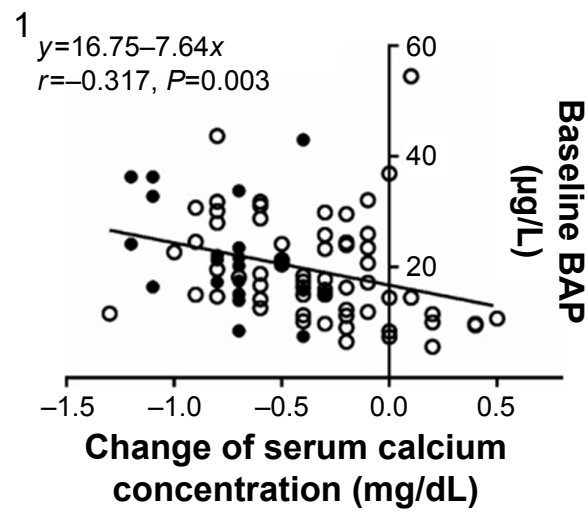

3

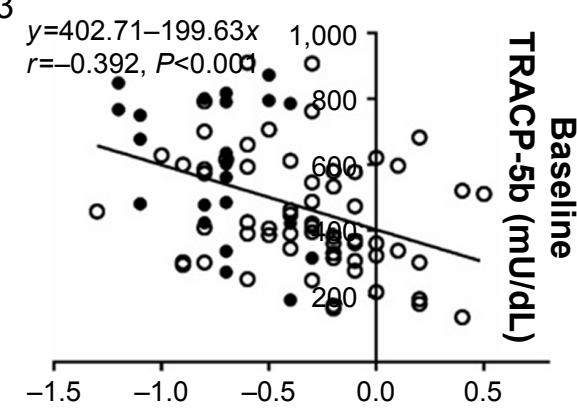

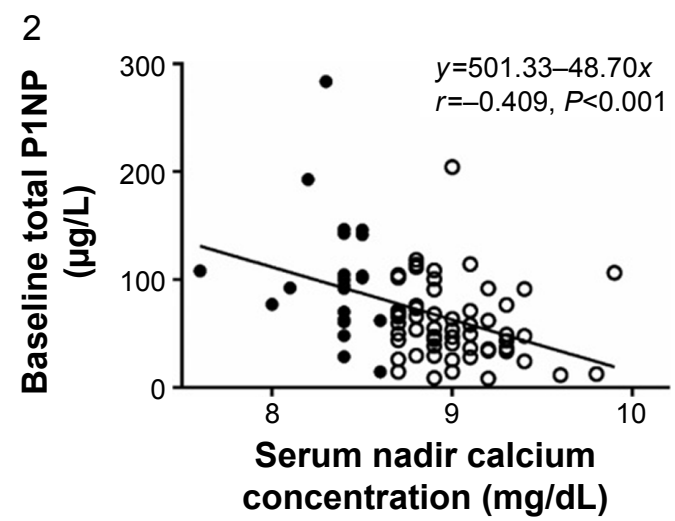

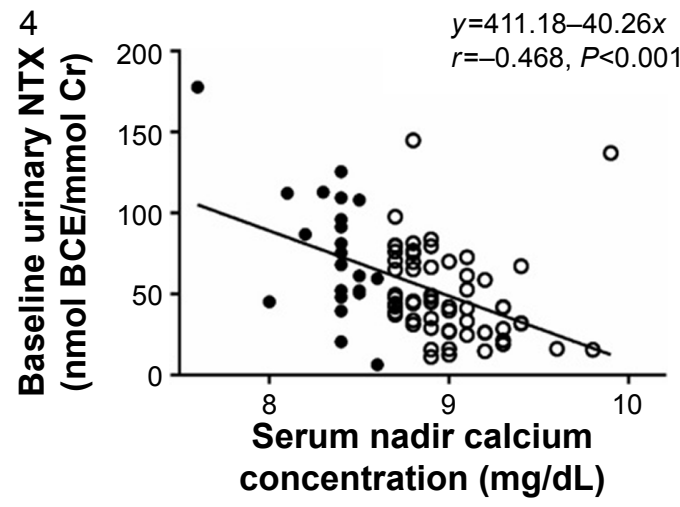

2

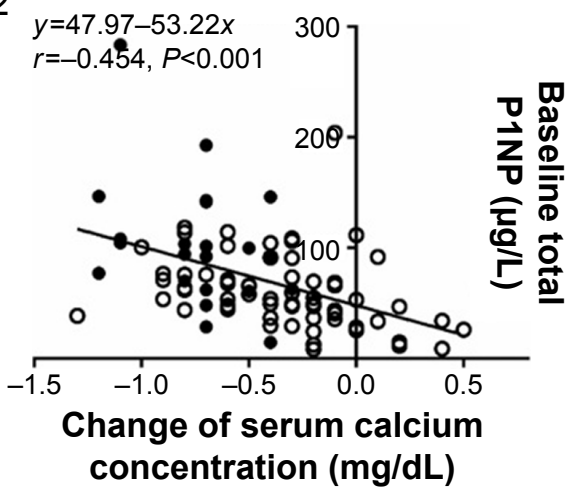

4

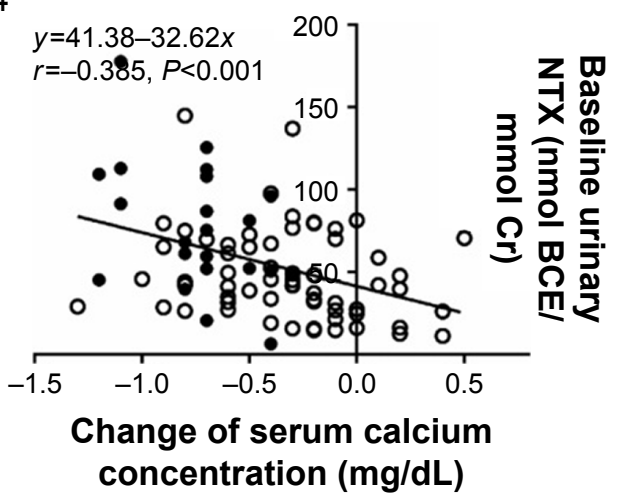

Figure 2 Relationships between baseline BTMs and serum calcium concentration changes following denosumab treatment.

Notes: Correlations between baseline BTMs and $(\mathbf{A})$ serum calcium concentration nadir and $(\mathbf{B})$ change in serum calcium concentration from baseline to nadir following denosumab treatment. Pearson's correlations are shown as $r$ values. Subpanels I-4 in each panel (A and B) represent the BTMs BAP, total PINP, TRACP-5b, and NTX, respectively. Solid circles represent patients with hypocalcemia, open circles show patients without hypocalcemia.

Abbreviations: BAP, bone-specific alkaline phosphatase; BTM, bone turnover marker; NTX, cross-linked N-telopeptide of type I collagen; PINP, N-terminal propeptide of type I procollagen; TRACP-5b, tartrate-resistant acid phosphatase $5 \mathrm{~b}$. 
Table 2 Univariate logistic regression analysis of risk factors for denosumab-induced hypocalcemia

\begin{tabular}{|c|c|c|}
\hline Factor & OR $(95 \% \mathrm{CI})$ & $P$-value \\
\hline Total PINP (per $10 \mu \mathrm{g} / \mathrm{L}$ increase) & $1.265(1.096-1.46 \mathrm{I})$ & $0.001 *$ \\
\hline TRACP-5b (per 10 mU/dL increase) & $1.041(1.013-1.070)$ & $0.004 *$ \\
\hline Urinary NTX (per $10 \mathrm{nmol} \mathrm{BCE} / \mathrm{mmol}$ & $1.300(1.100-1.537)$ & $0.002 *$ \\
\hline
\end{tabular}

Note: $* p<0.05$.

Abbreviations: OR, odds ratio; $\mathrm{Cl}$, confidence interval; PINP, N-terminal propeptide of type I procollagen; TRACP-5b, tartrate-resistant acid phosphatase $5 \mathrm{~b}$; NTX, cross-linked $\mathrm{N}$-telopeptide of type I collagen; BCE, bone collagen equivalent; Cr, creatinine.

CI: $1.466-14.405, P=0.009$; urinary NTX $>49.5 \mathrm{nmol}$ $\mathrm{BCE} / \mathrm{mmol} \mathrm{Cr}: \mathrm{OR}=4.749$, 95\% CI: $1.527-14.775$, $P=0.007)$. These results were approximately equal even after excluding the patients with prior treatment for osteoporosis ( $n=63$, data not shown).

\section{Discussion}

We found that high baseline bone turnover, as evidenced by several elevated BTMs, was associated with higher risk of denosumab-induced hypocalcemia. Thus, these BTMs could be useful predictors of hypocalcemia following denosumab treatment.

Of the 85 patients analyzed, 25.9\% developed hypocalcemia after administration of denosumab, higher than that recorded in previous reports. ${ }^{10,11}$ This greater incidence may be caused by earlier measurements of the values after denosumab administration (1-2 weeks after administration) and a higher normal serum calcium concentration range (lower limit: $8.7 \mathrm{mg} / \mathrm{dL}$ ) compared to that in previous studies (lower limit: $8.5 \mathrm{mg} / \mathrm{dL}) .{ }^{10,23} \mathrm{In}$ a preliminary report investigating the effect of a single $60 \mathrm{mg}$ denosumab dose with frequent monitoring of serum calcium concentration, 4 of 26 patients (15.4\%) with mild or moderate CKD (eGFR of $30-89 \mathrm{~mL} / \mathrm{min} / 1.73 \mathrm{~m}^{2}$ ) demonstrated a reduction in calcium concentration $<8.0 \mathrm{mg}$ / $\mathrm{dL} .{ }^{11}$ On the other hand, in a major clinical trial, only $1.5 \%$ of patients had serum calcium concentrations $<8.5 \mathrm{mg} / \mathrm{dL}$ 30 days after administration of a single $60 \mathrm{mg}$ denosumab dose. ${ }^{23}$ Although denosumab-induced hypocalcemia incidence has varied considerably across studies, in general, time to nadir is approximately 1-2 weeks. ${ }^{24,25}$ Indeed, in the current study, serum calcium concentration reached a nadir by that time in 45 of 85 patients $(52.9 \%)$. Therefore, monitoring of calcium concentrations before and during the first 2 weeks after denosumab administration is recommended.

While a sizeable minority developed hypocalcemia, only 1 patient developed grade 2 hypocalcemia (corrected serum calcium concentration of 7.9-7.0 mg/dL). All patients who developed hypocalcemia were asymptomatic (although symptoms are not always linked to hypocalcemia severity) and recovered quickly after receiving temporary oral calcium (1,000-3,000 mg/daily). It is possible that severe hypocalcemia was mitigated by this oral calcium supplementation. To identify risk factors for hypocalcemia, we first compared various baseline clinical demographic parameters between hypocalcemic and normocalcemic patients following denosumab administration. Although patients who developed hypocalcemia had normal baseline calcium concentrations, the mean was slightly lower than in those who did not have normal baseline calcium concentrations, consistent with recent findings by Autio et al. ${ }^{26}$ In contrast, other reports found no significant difference in baseline serum corrected calcium concentration between hypocalcemic and normocalcemic groups. ${ }^{17,18}$ Nevertheless, hypocalcemia should be corrected prior to administration of denosumab.

Although both BAP and total P1NP are categorized as bone formation markers, there was no correlation between BAP and hypocalcemia in univariate logistic regression analysis. This difference might be due to the fact that P1NP has several practical advantages, including its low diurnal variability and stability at room temperature, good precision, and low intraindividual variability. ${ }^{27}$ Multivariate logistic regression analysis revealed that higher baseline BTMs were significant independent risk factors for hypocalcemia induced by denosumab even after adjusting for baseline serum corrected calcium concentration and eGFR. Therefore,

Table 3 Multivariate logistic regression analysis of risk factors for denosumab-induced hypocalcemia

\begin{tabular}{|c|c|c|c|c|}
\hline Factor & OR $(95 \% \mathrm{CI})$ & $P$-value & Adjusted OR $(95 \% \mathrm{Cl})$ & $P$-value \\
\hline Total-PINP ( $\leq 76.5$ g/L) & I (reference) & - & I (reference) & - \\
\hline 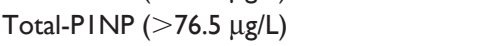 & $8.242(2.785-24.391)$ & $<0.00 I^{*}$ & $10.600(3.070-36.598)$ & $<0.00 I^{*}$ \\
\hline TRACP-5b ( $\leq 474 \mathrm{mU} / \mathrm{dL})$ & I (reference) & - & I (reference) & - \\
\hline TRACP-5b (>474 mU/dL) & $4.333(1.491-12.598)$ & $0.007^{*}$ & $4.596(1.466-14.405)$ & $0.009 *$ \\
\hline Urinary NTX ( $\leq 49.5 \mathrm{nmol} \mathrm{BCE} / \mathrm{mmol} \mathrm{Cr})$ & I (reference) & - & I (reference) & - \\
\hline Urinary NTX $(>49.5 \mathrm{nmol} \mathrm{BCE} / \mathrm{mmol} \mathrm{Cr})$ & $4.970(|.702-14.5| 4)$ & $0.003 *$ & $4.749(1.527-14.775)$ & $0.007 *$ \\
\hline
\end{tabular}

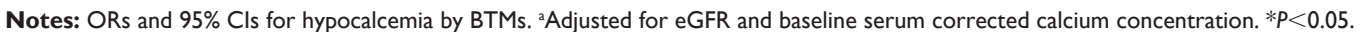

Abbreviations: PINP, N-terminal propeptide of type I procollagen; TRACP-5b, tartrate-resistant acid phosphatase 5b; NTX, cross-linked N-telopeptide of type I collagen; $\mathrm{BCE}$, bone collagen equivalent; $\mathrm{Cr}$, creatinine; OR, odds ratio; $\mathrm{Cl}$, confidence interval; $\mathrm{BTM}$, bone turnover marker; eGFR, estimated glomerular filtration rate. 
we suggest that these BTMs may be useful noninvasive clinical markers to predict hypocalcemia in clinical practice. Although the underlying mechanisms remain to be studied, it is possible that patients dependent on high bone turnover to maintain normal serum calcium concentrations are more sensitive to bone turnover inhibition by denosumab. Some earlier reports support this interpretation. The majority of patients in a couple of studies developed hypocalcemia after a first dose of either $60 \mathrm{mg}$ or $120 \mathrm{mg}$ denosumab. ${ }^{14,26}$ This may be explained by most patients having low bone turnover after the first course of denosumab. Furthermore, some previous studies ${ }^{17,18}$ have reported that prior use of zoledronic acid reduced the incidence of denosumab-induced hypocalcemia. Although they provided other reasons, this effect is most likely because of the induction of low bone turnover after zoledronic acid administration. Secondary hyperparathyroidism has been suggested to increase the risk of hypocalcemia. ${ }^{8,11}$ It is generally agreed that secondary hyperparathyroidism accelerates bone resorption and formation. These evidences strongly suggest that high bone turnover is associated with hypocalcemia.

Unlike several previous studies, kidney insufficiency did not appear to be a risk factor for denosumab-induced hypocalcemia in the current study. ${ }^{11,17,18}$ The reasons for these are as follows: 1) Only patients with relatively mild renal impairment were included. To focus on searching for the other factors leading to hypocalcemia. 2) All patients received prophylactic drugs (active vitamin D and calcium), and previous studies showing that lower baseline eGFR values are a significant risk factor for hypocalcemia included patients who did not receive supplementation. ${ }^{11,18} 3$ ) We used eldecalcitol, which is approved for the treatment of osteoporosis in Japan as a prophylactic drug for all patients. ${ }^{28,29}$ Eldecalcitol $-1 \alpha$, 25-dihydroxy-2 $\beta$-(3-hydroxypropyloxy) vitamin $\mathrm{D}_{3}-$ is an orally administered analog of $1 \alpha, 25$-dihydroxyvitamin $\mathrm{D}_{3}$, otherwise known as calcitriol or $1,25(\mathrm{OH})_{2} \mathrm{D}_{3}$. As it has a longer half-life with lower clearance rate and stronger vitamin D receptor-mediated effects than alfacalcidol, eldecalcitol is more effective for increasing serum calcium concentration than alfacalcidol. ${ }^{30}$

Elevated PTH following denosumab administration also contributed to serum calcium maintenance. PTH acts to increase the serum concentration of calcium by promoting the formation of $1,25(\mathrm{OH})_{2} \mathrm{D}$ within the kidney, thereby facilitating calcium absorption by the small intestine, and by augmenting active renal calcium absorption. ${ }^{31}$

Although we did not identify other factors associated with hypocalcemia induced by denosumab, comorbidities impairing calcium absorption may have also contributed to the development of hypocalcemia. It is well known that glucocorticoids decrease intestinal calcium absorption by decreasing calcium channel expression in the duodenum and by increasing calcium loss through the kidneys. ${ }^{32-34}$ Similarly, patients with a history of gastrointestinal surgery may be at a higher risk of denosumab-induced hypocalcemia. ${ }^{35}$

\section{Limitations}

The current study has several limitations. 1) The number of patients was not large enough to draw conclusions on the risk of severe hypocalcemia. 2) We did not assess the effect of severe renal impairment. Further prospective analyses with more patients, including those with severe renal dysfunction, are warranted. 3) In routine medical practice, the background of patients might vary widely compared to that of the patients in this study. For instance, patients who have suffered a fracture within a year before denosumab administration might exhibit differences in changes in their BTMs. ${ }^{36}$ 4) Although patients with osteoporosis are more likely to have a history of inadequate dietary calcium intake, ${ }^{37}$ we could not evaluate the oral calcium intake of the patients in daily life. 5) We were unable to assess the effect of $25(\mathrm{OH}) \mathrm{D}$, because we did not correct for $25(\mathrm{OH}) \mathrm{D}$ at baseline. However, vitamin D deficiency is strongly associated with serum calcium concentrations because 1,25-dihydroxyvitamin D stimulates calcium absorption in the intestines and bone mineralization. ${ }^{38}$

\section{Conclusion}

This is the first study to demonstrate an association between high bone turnover and risk of denosumab-induced hypocalcemia. We suggest that BTMs are potentially useful for prediction of hypocalcemia following denosumab treatment. Appropriate assessments before administration of denosumab, including baseline serum calcium, phosphorus, PTH, vitamin D, and eGFR, will help identify patients at greater risk of hypocalcemia induced by denosumab. Routine measurement of serum calcium concentrations approximately 1-2 weeks after denosumab administration is recommended for patients with high bone turnover for timely detection and early treatment initiation.

\section{Acknowledgment}

The authors thank Ayano Oyamada, Miyoko Kashiwagi, Tatsuyo Shinohara, Masayuki Arai, Kodai Hirabayashi, Noriyuki Hemmi, Syusuke Momma, Kenichirou Fukuda, Ryo Higuchi, and Kenji Dohi for their cooperation with osteoporosis treatment and technical assistance. 


\section{Disclosure}

The authors report no conflicts of interest in this work.

\section{References}

1. Cummings SR, San Martin J, McClung MR, et al. Denosumab for prevention of fractures in postmenopausal women with osteoporosis. N Engl J Med. 2009;361(8):756-765.

2. Keaveny TM, McClung MR, Genant HK, et al. Femoral and vertebral strength improvements in postmenopausal women with osteoporosis treated with denosumab. J Bone Miner Res. 2014;29(1):158-165.

3. Tsai JN, Uihlein AV, Burnett-Bowie SA, et al. Comparative effects of teriparatide, denosumab, and combination therapy on peripheral compartmental bone density, microarchitecture, and estimated strength the DATA-HRpQCT Study. J Bone Miner Res. 2015;30(1):39-45.

4. Papapoulos S, Lippuner K, Roux C, et al. The effect of 8 or 5 years of denosumab treatment in postmenopausal women with osteoporosis: results from the FREEDOM Extension study. Osteoporos Int. 2015 26(12):2773-2783.

5. Ferrari S, Adachi JD, Lippuner K, et al. Further reductions in nonvertebral fracture rate with long-term denosumab treatment in the FREEDOM open-label extension and influence of hip bone mineral density after 3 years. Osteoporos Int. 2015;26(12):2763-2771.

6. Parthan A, Kruse M, Agodoa I, Silverman S, Orwoll E. Denosumab: a cost-effective alternative for older men with osteoporosis from a Swedish payer perspective. Bone. 2014;59:105-113.

7. Hiligsmann M, Reginster JY. Cost effectiveness of denosumab compared with oral bisphosphonates in the treatment of post-menopausal osteoporotic women in Belgium. Pharmacoeconomics. 2011;29(10): 895-911.

8. Farinola N, Kanjanapan Y. Denosumab-induced hypocalcaemia in high bone turnover states of malignancy and secondary hyperparathyroidism from renal failure. Intern Med J. 2013;43(11):1243-1246.

9. Ungprasert P, Cheungpasitporn W, Srivali N, Kittanamongkolchai W, Bischof EF. Life-threatening hypocalcemia associated with denosumab in a patient with moderate renal insufficiency. Am J Emerg Med. 2013;31(4):756.

10. Anastasilakis AD, Toulis KA, Polyzos SA, Anastasilakis CD, Makras P. Long-term treatment of osteoporosis: safety and efficacy appraisal of Denosumab. Ther Clin Risk Manag. 2012;8:295-306.

11. Block GA, Bone HG, Fang L, Lee E, Padhi D. A single-dose study of denosumab in patients with various degrees of renal impairment. J Bone Miner Res. 2012;27(7):1471-1479.

12. Stopeck AT, Lipton A, Body JJ, et al. Denosumab compared with zoledronic acid for the treatment of bone metastases in patients with advanced breast cancer: a randomized, double-blind study. J Clin Oncol. 2010;28(35):5132-5139

13. Fizazi K, Carducci M, Smith M, et al. Denosumab versus zoledronic acid for treatment of bone metastases in men with castration-resistant prostate cancer: a randomised, double-blind study. Lancet. 2011; 377(9768):813-822.

14. Lechner B, DeAngelis C, Jamal N, et al. The effects of denosumab on calcium profiles in advanced cancer patients with bone metastases. Support Care Cancer. 2014;22(7):1765-1771.

15. Amgen Inc. $X G E V A^{\circledR}$ (Denosumab): Highlight of Prescribing Information. 2015. Available from: http://pi.amgen.com/united_states/xgeva/ xgeva_pi.pdf. Accessed February 14, 2016.

16. Buonerba C, Caraglia M, Malgieri S, et al. Calcitriol: a better option than vitamin D in denosumab-treated patients with kidney failure? Expert Opin Biol Ther. 2013;13(2):149-151.

17. Ikesue H, Tsuji T, Hata K, et al. Time course of calcium concentrations and risk factors for hypocalcemia in patients receiving denosumab for the treatment of bone metastases from cancer. Ann Pharmacother. 2014; 48(9):1159-1165.

18. Okada N, Kawazoe K, Teraoka K, et al. Identification of the risk factors associated with hypocalcemia induced by denosumab. Biol Pharm Bull. 2013;36(10):1622-1626.
19. Yonemori K, Fujiwara Y, Minami H, et al. Phase 1 trial of denosumab safety, pharmacokinetics, and pharmacodynamics in Japanese women with breast cancer-related bone metastases. Cancer Sci. 2008;99(6):1237-1242.

20. Committee of the Japan Diabetes Society on the Diagnostic Criteria of Diabetes Mellitus; Seino Y, Nanjo K, Tajima N, et al. Report of the committee on the classification and diagnostic criteria of diabetes mellitus. J Diabetes Investig. 2010;1(5):212-228.

21. Soen S, Fukunaga M, Sugimoto T, et al; Japanese Society for Bone and Mineral Research and Japan Osteoporosis Society Joint Review Committee for the Revision of the Diagnostic Criteria for Primary Osteoporosis. Diagnostic criteria for primary osteoporosis: year 2012 revision. J Bone Miner Metab. 2013;31(3):247-257.

22. Matsuo S, Imai E, Horio M, et al. Collaborators developing the Japanese equation for estimated GFR. Revised equations for estimated GFR from serum creatinine in Japan. Am J Kidney Dis. 2009;53(6):982-992.

23. EMA. CHMP Assessment Report for Prolia (Study 20040245). Available from: http://www.ema.europa.eu/docs/en_GB/document_library/ EPAR_-_Public_assessment_report/human/001120/WC500093529. pdf. Accessed December 24, 2015.

24. Papapoulos S, Chapurlat R, Libanati C, et al. Five years of denosumab exposure in women with postmenopausal osteoporosis: results from the first two years of the FREEDOM extension. J Bone Miner Res. 2012;27(3):694-701.

25. Healthy Canadians [webpage on the Internet]. Health Canada Endorsed Important Safety Information on XGEVA (Denosumab). 2012. Available from: http://www.healthycanadians.gc.ca/recall-alert-rappel-avis/ hc-sc/2012/14811a-eng.php. Accessed August 28, 2015.

26. Autio KA, Farooki A, Glezerman IG, et al. Severe hypocalcemia associated with denosumab in metastatic castration-resistant prostate cancer: risk factors and precautions for treating physicians. Clin Genitourin Cancer. 2015;13(4):e305-e309.

27. Garnero P, Vergnaud P, Hoyle N. Evaluation of a fully automated serum assay for total N-terminal propeptide of type I collagen in postmenopausal osteoporosis. Clin Chem. 2008;54(1):188-196.

28. Sakai A, Ito M, Tomomitsu T, et al. Efficacy of combined treatment with alendronate (ALN) and eldecalcitol, a new active vitamin D analog, compared to that of concomitant ALN, vitamin D plus calcium treatment in Japanese patients with primary osteoporosis. Osteoporos Int. 2015; 26(3):1193-1202.

29. Xu Z, Fan C, Zhao X, Tao H. Treatment of osteoporosis with eldecalcitol, a new vitamin $\mathrm{D}$ analog: a comprehensive review and meta-analysis of randomized clinical trials. Drug Des Devel Ther. 2016;10:509-517.

30. Matsumoto T, Ito M, Hayashi Y, et al. A new active vitamin D3 analog, eldecalcitol, prevents the risk of osteoporotic fractures - a randomized, active comparator, double-blind study. Bone. 2011;49(4):605-612.

31. Cozzolino M, Gallieni M, Brancaccio D, Arcidiacono T, Bianchi G, Vezzoli G. Vitamin D retains an important role in the pathogenesis and management of secondary hyperparathyroidism in chronic renal failure. J Nephrol. 2006;19(5):566-577.

32. Canalis E, Mazziotti G, Giustina A, Bilezikian JP. Glucocorticoidinduced osteoporosis: pathophysiology and therapy. Osteoporos Int. 2007;18(10):1319.

33. Wajchenberg BL, Pereira VG, Kieffer J, Ursic S. Effect of dexamethasone on calcium metabolism and $47 \mathrm{Ca}$ kinetics in normal subjects. Acta Endocrinol (Copenh). 1969;61(1):173.

34. Huybers S, Naber TH, Bindels RJ, Hoenderop JG. Prednisolone-induced $\mathrm{Ca} 2+$ malabsorption is caused by diminished expression of the epithelial Ca2+ channel TRPV6. Am J Physiol Gastrointest Liver Physiol. 2007;292(1):G92.

35. Bikle DD. Vitamin D insufficiency/deficiency in gastrointestinal disorders. J Bone Miner Res. 2007;22:V50-V54.

36. Nakamura Y, Kamimura M, Ikegami S, Mukaiyama K, Uchiyama S, Kato H. Change in bone turnover markers and fracture in osteoporosis: a review of the literature. Ann Orthop Rheumatol. 2014;2(3):1023.

37. Sunyecz JA. The use of calcium and vitamin D in the management of osteoporosis. Ther Clin Risk Manag. 2008;4(4):827-836.

38. Lips P. Vitamin D physiology. Prog Biophys Mol Biol. 2006;92(1):4-8. 


\section{Publish your work in this journal}

Therapeutics and Clinical Risk Management is an international, peerreviewed journal of clinical therapeutics and risk management, focusing on concise rapid reporting of clinical studies in all therapeutic areas, outcomes, safety, and programs for the effective, safe, and sustained use of medicines. This journal is indexed on PubMed Central, CAS,

EMBase, Scopus and the Elsevier Bibliographic databases. The manuscript management system is completely online and includes a very quick and fair peer-review system, which is all easy to use. Visit http://www.dovepress.com/testimonials.php to read real quotes from published authors.

Submit your manuscript here: http://www.dovepress.com/therapeutics-and-clinical-risk-management-journal 